\title{
PENERAPAN JARINGAN LAN DENGAN SISTEM REDUDANCY STATIC ROUTE MENGGUNAKAN ROUTER MIKROTIK PADA PT. SISTEM AKSESINDO PERDANA JAKARTA
}

\author{
1) Sari Dewi, ${ }^{2)}$ Yuliantama \\ 1) Manajemen Informatika, AMIK BSI Pontianak \\ sari.sre@bsi.ac.id \\ 2) Teknik Komputer, AMIK BSI Jakarta \\ yuliantama@live.com
}

\begin{abstract}
Computer networks are very important in supporting the company's operations, particularly for purposes of monitoring or update customer data, but current computer network PT. Sistem Aksesindo Perdana has only the internet access point, but it is also the only one internet lines often have dowtime or die on its Internet lines. Implementation of network Redudancy by using static router is the right solution to solve that problem because the protocol method has a level Service Level Agreement (SLA) is very high. With the implementation of network Redudancy to minimize downtime or dead tissue PT. Solusi Aksesindo Perdana, so as to increase effectiveness and efficiency in supporting the company's operations mainly for the purposes of monitoring and update customer data. In addition the system also can run automatically without controlled by the network administrator there.
\end{abstract}

\section{Keywords: Lokal Area Network (LAN), Redudancy (Failover),Mikrotik}

Abstrak - Jaringan komputer sangat penting dalam menunjang operasional perusahaan, terutama untuk keperluan monitoring atau update data pelanggan, namun saat ini jaringan komputer PT. Sistem Aksesindo perdana hanya memiliki satu jalur akses internet, selain itu juga dengan hanya satu jalur internet sering mengalami dowtime atau mati pada jalur internetnya. Peranan jaringan Redudancy dengan menggunakan metode static route merupakan solusi yang tepat untuk mengatasi permasalahan tersebut karena metode protokol tersebut memiliki tingkat Service Level Agreement (SLA) yang sanga tinggi. Dengan diterapkannya jaringan Redudancy dapat meminimalisir waktu downtime atau mati pada jaringan PT. Sistem Aksesindo Perdana, Tujuan dari system redundansi ini dimaksudkan untuk menjamin ketersediaannya layanan dimana tidak ada satupun titik rawan kegagalan. sehingga dapat meningkatkan efektifitas dan efisiensi dalam menunjang operasional perusahaan terutama untuk keperluan monitoring dan update data pelanggan. Selain itu juga sistem ini dapat berjalan otomatis tanpa harus dikendalikan oleh admin jaringan disana.

\section{Kata Kunci: Lokal Area Network (LAN), Redudancy (Failover), Mikrotik}

\section{A. PENDAHULUAN}

Perkembangan teknologi informasi pada saat ini berkembang sangat pesat, Internet telah membawa dampak yang begitu berarti pada berbagai aspek kehidupan manusia. Salah satu cara untuk mendapatkan informasi yang paling murah, cepat dan up to date (terbaru) adalah dengan menggunakan internet. Dalam menggunakan jasa internet setiap pengguna sudah pasti menginginkan kecepatan akses internet yang maksimal. Kecepatan akses internet tentunya akan berhubungan dengan besarnya kecepatan bandwidth yang tersedia dalam suatu jaringan. Saat ini, begitu banyak kasus - kasus permasalahan jaringan yang sering kita dapati pada jaringan komputer, antara lain data dan informasi yang dikirimkan sangat lambat, rusak, bahkan tidak sampai tujuan, komunikasi sering mengalami time-out (terputus), hingga masalah management perangkat untuk efisiensi pengguna perangkat yang ada. Ini tentunya berakibat fatal apabila downtime pada akses internet dan menurunnya performa kecepatan internet pada kinerja sebuah instansi. Sebab itu, jaringan komputer sangatlah memerlukan sebuah sistem backup yang berfungsi untuk2 meminimalisir downtime yang ada serta diperlukannya sebuah management dimana semua bisa tertata dengan baik pada sebuah jaringan. Menurut Towidjojo (2013:12) jika menginginkan menginginkan penerapan fail over pada jaringan traffic di jaringan tidak terlalu besar, sehingga tidak perlu dilakukan pembagian beban. hanya menyediakan adanya link cadangan di router sehingga network internal lebih handal. maka hal itu bisa disebut dengan redudancy atau lebih dikenal dengan bahasa teknis nya yaitu fail over. Definisi fail over dalam istilah komputer internetworking adalah kemampuan sebuah sistem untuk dapat berpindah secara manual maupun otomatis jika salah satu sistem mengalami kegagalan 
sehingga menjadi backup untuk sistem yang mengalami kegagalan. Fail over ini juga suatu teknik jaringan dengan memberikan dua jalur koneksi atau lebih dimana ketika salah satu jalur mati, maka koneksi masih tetap berjalan dengan disokong oleh jalur lainnya.Teknik fail over ini cukup penting ketika kita menginginkan adanya koneksi jaringan internet yang handal.

Oleh karena itu kelangsungan koneksi pada jaringan komputer mutlak diperlukan untuk menjaga kehandalan koneksi jaringan, tujuan adanya backup darisub sistem - sub sistem ini adalah untuk mengatasi jika terjadi kegagalan salah satu sub sistem maka sub sistem backup akan menggatikan fungsi yang gagal tersebut. PT. Sistem Aksesindo Perdana yang bergerak di bidang jasa yang mempunyai tugas salah satunya yaitu monitoring dan remote management ke setiap pelanggan yang tersebar di daerah Jakarta dan sekitarnya. Dalam hal pelaksanaannya, masih sering menemukan kendala seperti proses monitoring dan remote management lambat bahkan bukan hanya itu monitoring dan remote management pun bisa teputus karena koneksi internetnya down, karena setiap akan melakukan monitoring dan remote management ke setiap pelanggannya harus menggunakan koneksi yang cepat dan stabil serta tidak terputus. Ketersediaan sistem cluster memiliki pengertian bahwa sebuah sistem yang dibangun akan terus menjaga kontinyuitas sistemnya dengan cara melakukan backup sistem jaringan server komputer (redundancy), failover apabila ada salah satu perangkat jaringan server yang bermasalah atau mati total maka load balancing akan membagi jalur akses dari client untuk mengakses ke server sehingga pemrosesan data maupun aplikasi dapat dilakukan lebih cepat [suryanto:2015] .Untuk menanggulangi hal tersebut maka dibutuhkanlah sebuah pengembangan sistem management di sebuah jaringan sehingga diharapkan dapat mengurangi kesulitan yang ada sehingga sistem bekerja secara optimal dalam melakukan pelayanan.

\section{B. TINJAUAN PUSTAKA}

Pembangunan jaringan yang kompleks dengan akurasi kestabilan komunikasi tinggi dilakukan dengan mengimplementasikan Redundancy. Menurut Choirullah (2016:278) VRRP menjaga dari terputusnya jalur komunikasi dan menjaga dari matinya router utama. Hal tersebut dikarenakan protokol VRRP menggunakan dua router yang berfungsi sebagai router master dan router backup. Tujuan dari dilakukannya analisis
VRRP adalah untuk memberikan informasi tentang kualitas layanan dari VRRP master backup yang dapat menstabilkan jaringan dari terputusnya jalur komunikasi dan nilai kualitas layanan VRRP master backup yang beradapada jaringan VLAN, dengan VRRP master backup yang berada di jaringan tanpa VLAN pada layanan cloud storage menggunakan router Mikrotik RB1100AHx2, dengan kualitas layanan yang akan dianalisis adalah downtime, delay, troughput, retransmission, dan packet loss. Manfaat dari analisis yang dilakukan adalah untuk memberikan informasi mengenai kualitas layanan protocol redundansi router, serta perbandingan antara topologi VLAN dengan topologi LAN, yang selanjutnya dapat berguna dalam pertimbangan pembuatan desain suatu jaringan.

\section{METODE PENELITIAN}

Dalam rangka pengumpulan data yang diperlukan dalam penulisan menggunakan beberapa metode, diantaranya adalah:

1. Analisis

a) Penulis melakukan pengamatan langsung terhadap proses kerja yang dilakukan dan melakukan wawancara terhadap Manager IT di PT. Sistem Aksesindo Perdana yang berada di Komplek Griya Inti Sentosa Jl. Griya Agung blok O 88-89 Jakarta khususnya bagian IT jaringan untuk mengumpulkan data dan informasi yang berkaitan dengan permasalahan yang ada di perusahan tersebut.

b) Studi Literatur yang merupakan teknik pengumpulan data atau informasi dengan mempelajari buku-buku yang berisi konsep dan implementasi Teknik Redudancy yang digunakan sebagi dasar dari pengembangan penulisan artikel ini

\section{Perancangan}

Perancangan jaringan ini melalui tahap pengujian dari sistem operasi mikrotik dalam hal ini mengunajkan Winbox untuk penyetingannya dan mengunakan GNS3 untuk penyetesan jaringan tersebut

\section{HASIL DAN PEMBAHASAN}

\section{Cluster}

Dalam ilmu komputer dan jaringan komputer adalah sekumpulan komputer (umumnya server jaringan) independen yang beroperasi serta bekerja secara erat dan terlihat oleh klien jaringanseolah-olah komputer-komputer tersebut adalah satu buah unit komputer. Proses menghubungkan beberapa komputer agar dapat bekerja seperti 
itu dinamakan dengan Clustering. Komponen cluster biasanya saling terhubung dengan cepat melaluisebuah interkoneksi yang sangat cepat, atau bisa juga melalui jaringan lokal (LAN). Karena menggunakan lebih dari satu buah server, maka manajemen dan perawatan sebuah cluster jauh lebih rumit dibandingkan dengan manajemen server mainframe tunggal yang memiliki skalabilitas tinggi (semacam IBM AS/400), High-availability adalah ilmu untuk menciptakan redundansi dalam setiapsistem dan subsistem untuk memastikanbahwa layanan tetap up dan tersedia. HA pada dasarnya menempatkan satu ataulebih server cadangan dalam modus siaga, yang bisa online dalam beberapa saat hanya setelah mereka menemukan kegagalan pada sistem utama. (Charles Bookman, 2002). High-availability cluster, yang juga sering disebut sebagai Failover Cluster pada umumnya diimplementasikan untuk tujuan meningkatkan ketersediaan layanan yang disediakan oleh kluster tersebut. Elemen kluster akan bekerja dengan memiliki nodenode redundan, yang kemudian digunakan untuk menyediakan layanan saat salah satu elemen kluster mengalami kegagalan. Ukuran yang paling umum dari kategori ini adalah dua node, yang merupakan syarat minimum untuk melakukan redundansi. Implementasi kluster jenis ini akan mencoba untuk menggunakan redundansi komponen kluster untukmenghilangkan kegagalan di satu titik (Single Point of Failure).

\section{Mikrotik}

Dikenal sebagai salah satu Router OS yang handal dan memiliki banyak sekali fitur untuk mendukung kelancaran network. Kelebihan Router Mikrotik adalah mudah dalam pengoperasian. Disebut mudah bila kita bandingkan dengan Router OSlain seperti Cisco dan lainnya. Kemudahan pengoperasian Router berbasis Mikrotik OS salah satunya adalah berkat tersedianya fitur GUI. Jadi kita bisa setup router tidak hanya melalui tampilan text yang biasa digunakan OS router lain, tapi juga bisa dilakukan melalui sebuah aplikasi remote berbasis GUI bernama Winbox. Kelebihan lain dari Mikrotik RouterOS adalah banyaknya fitur yang didukung. Fitur-fitur network yang terdapat pada Mikrotik OS tersebut adalah Routing - Static Routing, Hotspot, Simple Tunnels, Web Proxy,DHCP, VRRP, NTP, SNMP, MNDP, Firewall\& NAT, Data RateManagement, Pointto-Point Tunneling Protocols, IPsec, Caching DNS Client, Universal Client, UPnP, Monitoring/Accounting, M3P, Tools, dan masih banyak lainnya, termasuk support scripting programming.

\section{Analisa Jaringan}

Analisa pada jaringan komputer sangatlah penting agar bisa mengetahui kelebihan dan kekurangan dari jaringan tersebut. Adapun dari hasil analisa yang telah dilakukan, jaringan komputer yang ada di PT. Sistem Aksesindo Pedana merupakan jaringan komputer LAN (Local Area Network). Jaringan komputer LAN mempunyai sistem jaringan komputer yang terdiri dari Router 1 unit, Access Point 150 unit, HUB 6 unit, komputer 32 unit dan Printer 1 unit dan internet NETZAP sebagai koneksi internet.

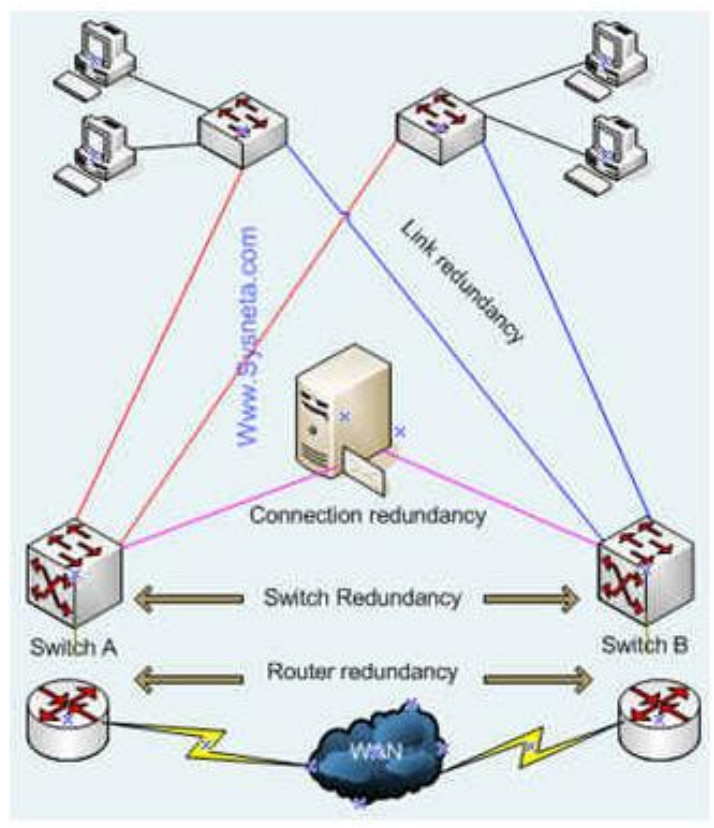

Gambar 1. Link Redudancy

Kebutuhan load balancing dan redundansi perlu dikaji untuk berdasarkan kebutuhan penggunaan link redundansi, piranti router, switch dan multi-homed host yang bersifat kritis. Tujuan dari system redundansi ini dimaksudkan untuk menjamin ketersediaannya layanan dimana tidak ada satupun titik rawan kegagalan.

Redundansi switch, jika terjadi masalah dikarenakan kegagalan pada switch $A$, Switch $B$ masih bisa berfungsi untuk mensuplay link kepada server dan juga ke dua distribusi switch dan link ke WAN. Permasalahan jaringan ini tidak akan mempengarui system server down. Redundansi router akan membuat backup link WAN saat terjadi masalah pada salah satu router. Misal salah satu router yang menghubungkan jaringan frame relay anda ke kantor lainnya, maka masih ada backup link di router satunya. 
Redundansi link - akan membackup link jika ada masalah jaringan dengan terputusnya link ke server atau ke switch. Kita bisa mengaplikasikan system redundansi ini pada model scenario sebelumnya yang menghubungkan kedua kantor Mining dan HRD dengan menarik dua kabel UTP Cat5e bawah tanah sebagai link redundansi. Pastikan bahwa kedua kabel redundansi ini tidak terhubung kepada switch yang sama, karena kalau terjadi kegagalan pada switch maka akan percuma juga.Untuk redundansi link internet, sebenarnya sudah banyak dipasaran router dengan port WAN dua atau lebih sehingga tidak perlu lagi dua router. Router jenis ini biasanya untuk kantoran kecil menengah dimana dua port WAN bisa failover - failback. Jadi jika link utama fail, maka akan failover ke link backup. Atau bisa juga kedua link dibuat load balancing, sebut saja FVS336G Dual Wan Gigabit SSL VPN Firewall.

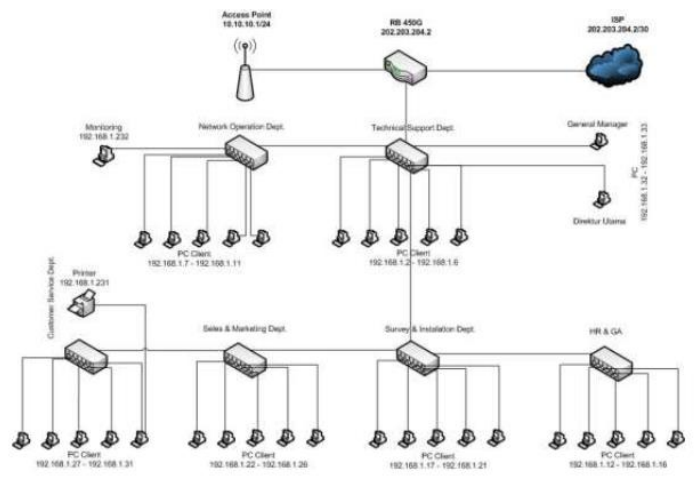

Gambar 2. Skema Jaringan Perusahan

Internet menggunakan ISP PT. Maxindo Content Solusi, Dari internet masuk ke router mikrotik RB450G ether 1 sebagai akses WAN, yang dimana router ini menjadi penghubung antara jaringan lokal dan jaringan publik PT.Sistem Aksesindo Perdana. Lalu dari ether 2 mikrotik RB450G terhubung ke hub sebagai pemberi akses jaringan lokal ke semua komputer client yangterhubung melalui kabel. Access point sebagai penyebar sinyal wireless ke semua client masuk ke router di ether 3 Dari HUB yang ada di skema menujukan bahwa terdapat 7 divisi yang menggunakan jaringan dengan kabel, dan internet dengan kecepatan 12 Mbps yang terbagi 32 unit komputer dengan masing-masing mendapatkan 256 Kbps pada setiap divisi yang ada lalu satu komputer monitoring yang mendapatkan 2 Mbps. Dengan sisa bandwidth yang ada di berikan untuk perangkat Access Point yang sering di gunakan oleh karyawan.

\section{Identifikasi Masalah}

Di PT. Sistem Aksesindo Perdana jaringan komputer yang digunakan bisa dikatakan baik, karena spesifikasi komponen perangkat keras (Hardware) maupun perangkat lunak (Software) sudah disesuaikan dengan kebutuhan.. Adapun permasalahan di PT. Sistem Aksesindo Perdana terjadi Ketika terjadi downtime pada koneksi internet tidak ada link backup. Jadi ketika koneksi internet down maka seluruh aktifikas yang berhungan dengan jaringan akan terputus hal ini berlaku baik jaringan internal maupun external.

\section{Pemecahan Masalah}

Setelah melakukan analisa dan melihat permasalahan jaringan komputer di PT. Sistem Aksesindo Perdana Adapun pemecahan masalahnya adalah Memberikan link backup pada jaringan komputer supaya ketika terjadi downtime pada link utama maka link backup menggantikan link utama.

\section{Prinsip Statik Routing}

Dalam menerapkan static routing statik, kita akan mengisikan entry route pada tabel routing secara manual disetiap router yang ada dalam jaringan. Entry tersebut diperlukan oleh router untuk mengetahui network tujuan dan bagaimana mencapai network tersebut. Sebuah routing statik yang akan dimasukkan ke tabel routing harus mengandung 3(tiga) informasi, yaitu :

a) Network Address, informasi ini merupakan network dari address network yang akan dituju (destination).

b) Subnet mask (prefix), informasi ini merupakan prrefix atau subnet mask dari network yang akan dituju (merupakan prefix dari network address pada point diatas.

c) Next Hop atau Gateway, informasi ini berguna untuk memberitahukan kepada router tentang bagaimana mencapai network tujuan yang telah didefinisikan di point 1. Next hop merupakan IP Address dari router tetangga yang dapat digunakan untuk mencapai network tujuan.

d) Lalu masukan IP public backup pada mikrotik router office 


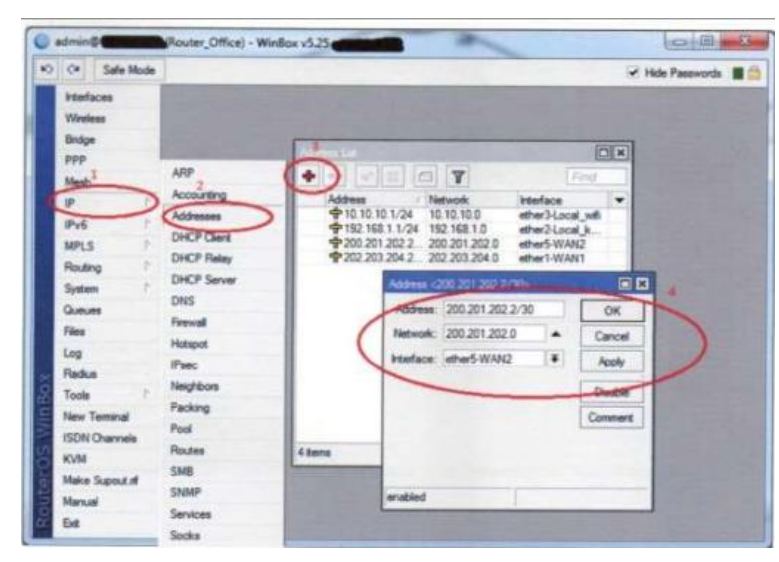

\section{IP Gateway Public}

Lalu masukan IP gateway publik backup pada mikrotik router office.

Gateway : :200.201.202.167

Check gateway : ping

Distance : 2 (sebagai prioritas ke-2)

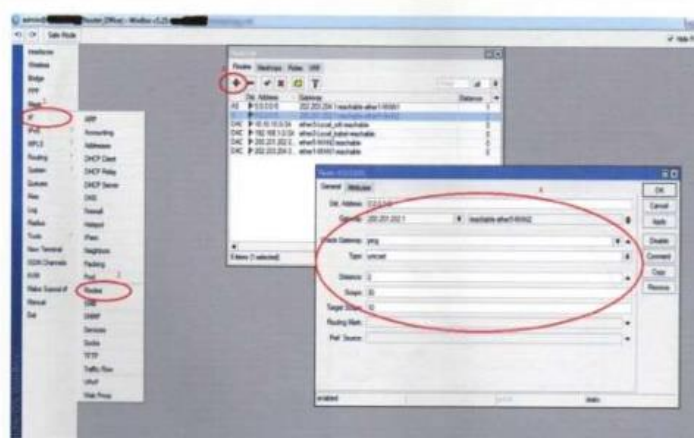

\section{Bridge Interface agar WAN1 dan WAN2 agar saling terhubung}

a) Klik tab bridge.

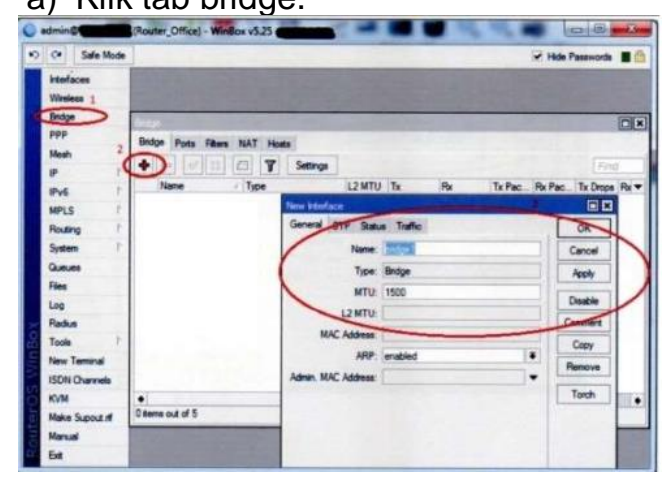

b) Klik tab port pada window bridge.

c) Klik "+" pada window pojok kiri atas yang berwarna merah untuk menambahkan interface yang akan di bridge ke mikrotik router office.

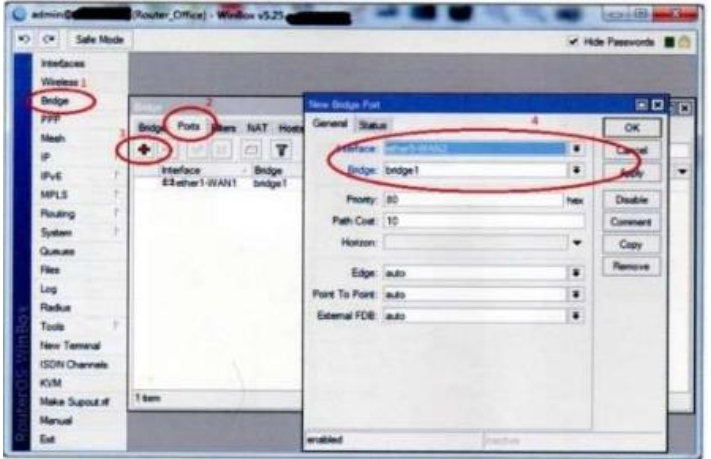

Selanjutnya adalah pengetesan link backup yang sudah dibuat apakah sudah siap digunakan atau tidak dengan cara ping ip gateway public dari router office.

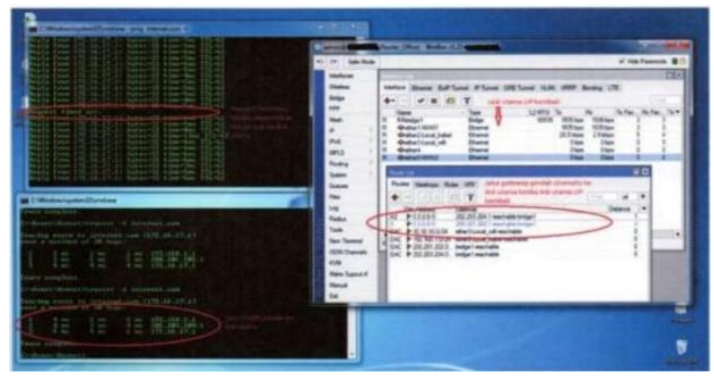

Dari gambar diatas penulis bisa menjelaskan bahwa koneksi tidak terputus saat link utama down atau mati, karena link backup langsung bekerja secara otomatis dan sistem redudancy ini tidak perlu repot untuk setting kembali jika link utama hidup kembali karena routing table akan berpindah secara otomatis juga ke link utama jika link utama sudah hidup kembali. Karena sistem backup sudah berjalan dengan opt imal maka koneksi backup yang penulis buat sudah berhasil dan bisa running dengan sendirinya, Berikut adalah tampilan untuk mengukur Availability Server.

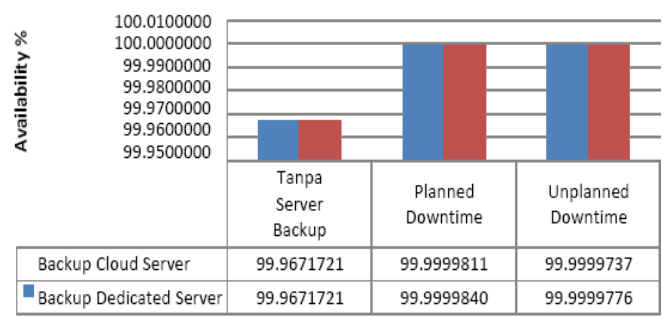

Gambar 3 Grafik Pengukuran Availability Server

Pada perhitungan availability pada planned downtime di backup server baik pada dedicated dan cloud didapatkan hasil 99.\% nilai tersebut masuk kedalam rekomendasi the-six nines artinya bahwa setiap tahunnya sistem tersebut akan mengalami down atau tidak dapat melayani permintaan client dengan waktu tidak lebih dari 31,5 detik. Bila 
dibandingkan dengan tanpa menggunakan backup server pada skenario planned yang memiliki availability sebesar tidak lebih dari 10 jam, 60 menit, dan 36 detik adalah jauh lebih baik. Hal ini membuktikan bahwa peran menggunakan backup server untuk menghandle kondisi jika terjadi down server adalah sangat efektif. Selain itu perhitungan diatas downtime dan availability dapat terlihat nilai yang dihasilkan saat backup server pada cloud dibandingkan pada backup dedicated lebih tinggi dikarenakan pada saat proses perpindahan (failover) ke cloud server paket harus melalui hypervisor yang menyebabkan paket akan tiba sedikit lebih lama. Sehingga availability yang dihasilkan pun berbeda namun masih masuk kedalam rekomendasi the-six nines sama seperti saat backup berada di dedicated.

Throughput Backup Server

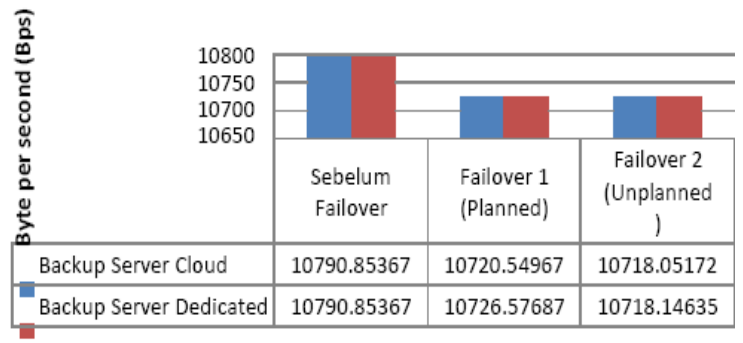
Gambar 4 Grafik Pengukuran Throughput
Server

Dari hasil grafik diatas menunjukan throughput saat sebelum failover memiliki nilai yang paling tinggi, sedangkan untuk skenario failover 2 atau unplanned mempunyai throughput yang paling rendah. Nilai throughput dipengaruh oleh codec dan bitrate yang digunakan saat proses komunikasi. Pada percobaan kali ini dilakukan dengan menggunakan codec G.711 dengan payload 160 bytes dan bitrate 64kbps, Hasil analisis diatas menunjukan nilai throughput keseluruhannya memiliki nilai diatas 10700 bytes/sec. Namun, perbedaan nilai terlihat ketika sebelum failover dan saat melakukan skenario failover 1 dan failover 2 . Penurunan throughput terjadi saat dilakukannya failover, hal ini dikarenakan saat terjadinya failover komunikasi tersebut akan terputus sehingga memerlukan proses redial untuk dapat berkomunikasi kembali, hal ini mengakibatkan paket yang sampai ditujuan dengan selang 1 menit akan lebih sedikit dibandingkan dengan sebelum failover yang tidak mengalami drop call.

\section{E. KESIMPULAN}

Berdasarkan

tinjauan pada bab sebelumnya dapat penulis tarik kesimpulan bahwa penerapan sistem redudancy dengan static route merupakan solusi yang tepat untuk mengatasi permasalahan yang ada pada jaringan komputer PT. Sistem Aksesindo Perdana saat ini. Karena sistem ini dapat membacku jaringan komputer secara otomatis, sehingga seolah-olah jaringan komputer PT. Sistem Aksesindo Perdana tidak mengalami downtime. Dengan diterapkannya sistem redudancy dengan static route pada jaringan komputer PT. Sistem Aksesindo Perdana diharapkan bisa meningkatkan efektifitas dan efisiensi dalam menunjang operasional perusahaan.

\section{DAFTAR PUSTAKA}

[1] Asteria, Devita .2015. Implementasi Dan Analisis Metode Failover Pada Sistem Redundant

[2] Dedicated Server Dan Cloud Server Untuk Layanan Voip: e-Proceeding of Engineering : Vol.2

[3] Bookman, Charles. 2002. Linux Clustering: Building and Maintaining Linux Clusters: United States of America. New Riders Publishing.

[4] Madcoms. 2013. Sistem Jaringan Komputer untuk Pemula, Andi :Yogyakarta

[5] Suryanto.2015. Implementasi Clustering Database Server Menggunakan Pgcluster Untuk Optimalisasi Kinerja Sistem Basis Data: Jurnal JTK BSI

[6] Syamsudin. 2013. 60 menit belajar monitoring Jaringan. buku digital.net: jakarta

[7] Towidjojo, Rendra. 2013. Mikrotik Kung Fu: Kitab 2. Jakarta: Jasakom.

[8] Choirullah , Muhammad Yusuf.2016. Analisis Kualitas Layanan Virtual Router Redundancy Protocol Menggunakan Mikrotik pada Jaringan VLAN: JNTETI, Vol. 5 , No. 4 